\title{
Complicated extracapsular cataract surgery in pseudoexfoliation syndrome: a case report
}

\author{
J N P Kirkpatrick, R A Harrad
}

\begin{abstract}
Crystalline lens dislocation and zonular dialysis during intraocular surgery are recognised features of the pseudoexfoliation syndrome (PES). A case is reported in which zonular dialysis occurred in both eyes during extracapsular cataract extraction. In particular surgery was complicated by difficulty in performing anterior capsulotomy. Careful preoperative assessment and peroperative technique may help to reduce the risk of surgical complication in PES.

(BrF Ophthalmol 1992; 76: 692-693)
\end{abstract}

Pseudoexfoliation syndrome (PES) is characterised by: (1) the presence of grey/white material on the anterior lens capsule and zonule; (2) trabecular meshwork pigmentation; and (3) an association with glaucoma which is usually of the open angle type.

Spontaneous and intraoperative crystalline lens dislocation, zonular dialysis, posterior capsule rupture, and vitreous loss have been described previously in PES. We report a case in which cataract extraction in both eyes was complicated by zonule dialysis.

Bristol Eye Hospital, Lower Maudlin Street, Bristol

J N P Kirkpatrick

R A Harrad

Correspondence to: J N P Kirkpatrick, Ophthalmology Department, Aberdeen Royal Infirmary, Foresterhill, Aberdeen AB9 2ZB.

Accepted for publication 9 June 1992

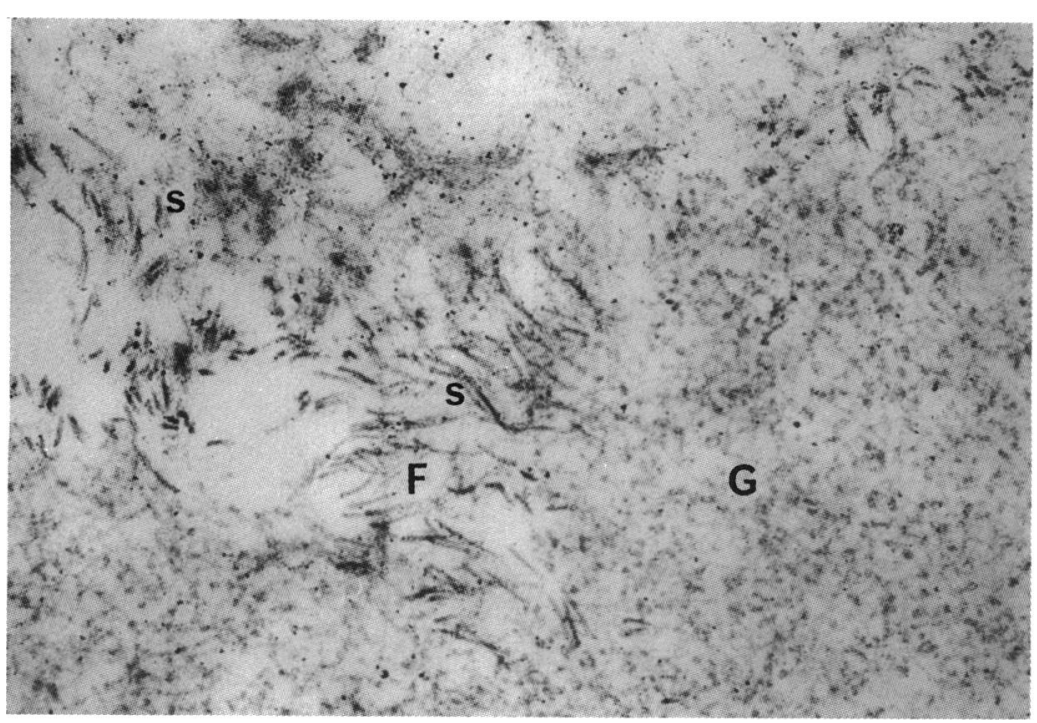

Figure 1 Ultrastructure of pseudoexfoliative material. Both granular $(G)$ and fibrillar $(F)$ components are demonstrated. Note the fine striations $(S)$ which correspond to the $50 \mathrm{~nm}$ banded zones in pseudoexfoliation $(\times 34500)$
Visual acuity was $6 / 24$ unaided $(6 / 12$ pinhole acuity) in the right eye and hand movements in the left eye. The right eye showed a nuclear cataract and a deep anterior chamber with normal intraocular pressure (IOP). The left eye had a shallow anterior chamber, closed iridocorneal angle, raised intraocular pressure at $31 \mathrm{~mm} \mathrm{Hg}$, and a mature cataract. There was pseudoexfoliative material in both eyes.

The patient was admitted for medical control of IOP and then underwent left cataract extraction 3 days after admission. During planned extracapsular surgery the anterior capsulotomy was performed with difficulty owing to the marked toughness of the capsule. After nuclear expression the lens equator was visible inferiorly consistent with a large zonular dialysis. The posterior capsule, soft lens matter, and anterior vitreous were removed using a Kaufmann vitrector. An anterior chamber intraocular lens was inserted. The postoperative course was immediately complicated by raised IOP which was followed by streptococcal endophthalmitis after 48 hours. Despite intensive antibiotic therapy the left eye became painful and blind necessitating evisceration after 2 months.

At follow up after 1 year vision in the right eye had deteriorated to counting fingers and he was readmitted for cataract surgery. At this admission the eye showed increasing nuclear cataract, normal IOP, and there was minimal phakodonesis.

At surgery the lens was quite mobile and capsulotomy proved extremely difficult. It was only possible to make an incomplete canopener capsulotomy with a bent 27 gauge needle which was then augmented with anterior capsule scissors. When using scissors the capsule seemed to be unusually tough. The capsular flap was removed successfully but following nuclear expression there was an inferior zonule dialysis. After administration of chymotrypsin the posterior capsule was removed with forceps (without vitreous loss), peripheral iridectomy was performed, and an anterior chamber intraocular lens was inserted. The postoperative phase was entirely unremarkable and the patient achieved $6 / 6$ vision with suitable refraction. The lens capsule was sent for histological and ultrastructural analysis.

\section{HISTOPATHOLOGY}

Light microscopy demonstrated the presence of periodic acid Schiff positive material on the external surface of the lens capsule. The lens epithelium varied from attenuated cells to more cuboidal cells containing cytoplasmic vacuoles. Transmission electron microscopy showed 
normal capsule appearances in the region where there is no pseudoexfoliative material (PXE). Where PXE material was present on the preequatorial and central disc areas of the anterior capsule there were focal condensations of fibrillogranular material with cross banding at 50 $\mathrm{nm}$ and more clearly at 4-5 $\mathrm{nm}$ (Fig 1). There appeared to be no other additional pathological features.

\section{Discussion}

Spontaneous lens dislocation and complications during both intra and extracapsular surgery in PES have been reported frequently. ${ }^{1-4}$ Results from a large series of 2042 eyes undergoing cataract extraction by Naumann et al estimate prevalence of PES at $3 \cdot 5 \%$ (72 eyes). ${ }^{5}$ The rate of vitreous loss in those with PES was $11 \cdot 1 \%$ compared with $1.6 \%$ in those without PES $(p<0.0001)$. The incidence of posterior capsule rupture was not significantly different in either group which suggests that vitreous loss was related directly to zonule dialysis rather than capsule weakness. In addition a further series of 977 patients undergoing cataract surgery (241 with PES) reported by Guzek et al showed that there was an association between zonular breaks and PES but that there was no increase in the rate of vitreous loss in these patients. ${ }^{6}$

Careful preoperative assessment in PES patients for cataract extraction is essential for avoidance of peroperative complications. Specific signs indicating zonule weakness are lens subluxation, phakodonesis, narrow iridocorneal angle, and anterior chamber asymmetry. Interestingly iridodonesis may well not accompany phakodonesis as the iris appears to have increased rigidity being infiltrated by PXE material. ${ }^{37}$ This factor may also explain the poor pupillary dilatation in PES patients after mydriatic instillation. Jofe reports that phakodonesis in PES is very difficult to see after pupil dilatation and recommends close examination for phakodonesis prior to dilatation. ${ }^{8}$ Angle closure glaucoma as occurred in this case has been attributed to lens mobility ${ }^{9}$ but could also be caused by increasing lens size should intumescence develop.

Intraoperative difficulty in cataract extraction in PES patients may be the result of poor pupillary dilatation, excessive lens mobility, iris rigidity, adherence of iris to peripheral lens capsule, ${ }^{10}$ difficult nucleus expression, or zonule dialysis with vitreous loss. ${ }^{3}$ In our case the most prominent factor causing surgical difficulty was the toughness of the lens capsule in addition to lens movement. The inability of a standard cystotome to perform an adequate capsulotomy and the need for capsule scissors has not been reported. This factor together with zonule laxity was the cause of surgical complication in both eyes.

Histological and ultrastructural findings in this case concur with the reported data on PES. ${ }^{7}$ One would expect to find PXE material on the pre-equatorial and central disc areas of the anterior lens separated by a relatively clear band. The PXE material consists of fibres which have a recognisable ultrastructural appearance of cross banding at $4-5 \mathrm{~nm}$ and $50 \mathrm{~nm}$ and characteristic histochemical properties. The lens capsule was of normal thickness, but it is possible that either the capsule itself becomes tougher in PES or that the deposit of PXE material on the capsule alters the characteristics of the capsule during surgery. If it is presence of PXE material on the iris which contributes to increased rigidity it could have a similar effect on the lens capsule. No other structural abnormality in this case could explain undue toughness of the lens capsule.

The complications described above are relatively common in PES and cases require careful preoperative consideration. Application of the appropriate techniques such as sphincterotomy for small pupils and intracapsular surgery for incipient lens subluxation may be necessary. Where a posterior chamber lens is to be used careful cortical lens matter aspiration and implantation of the lens using viscoelastic agents without dialling is advised. Tarkanen suggests the intentional placement of posterior chamber intraocular lenses in the ciliary sulcus rather than risk strain on a weak zonule. ${ }^{11}$ The use of anterior chamber intraocular lenses in patients predisposed to glaucoma carries a risk of further damage to an already compromised drainage angle and may not be advisable.

1 Gradle HS, Sugar HS. Concerning the chamber angle: 2 Exfoliation of the zonular lamella and glaucoma capsulare. Exfoliation of the zonular lamella and

2 Irvine R. Exfoliation of the lens capsule (glaucoma capsularis): forty cases of exfoliation. Arch Ophthalmol 1940; 23: 13850.

3 Skuta GL, Parrish RK, Hodapp E, Forster RK, Rockwood EJ. Zonular dialysis during extracapsular cataract extraction in pseudoexfoliation syndrome. Arch Ophthalmol 1987; 105: $632-4$.

4 Bartholomew RS. Phakodonesis: a sign of incipient lens displacement. Br f Ophthalmol 1970; 54: 663-6.

5 Naumann GO, Kuchle M, Schonherr U. Pseudo-exfoliation syndrome as a risk factor for vitreous loss in extracapsular cataract extraction. The Erlangen Eye Information Group. Fortschr Ophthalmol 1989; 86: 543-5.

6 Guzek JP, Holm M, Cotter J, Cameron JA, Rademaker WJ,

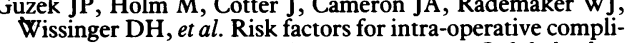
cations in 1000 extracapsular cataract cases. Ophthalmology cations in 1000 .

7 Dark AJ, Streeten BW. Pseudoexfoliation syndrome. In: Garner A, Klintworth GK, eds. Pathobiology of ocular disease. A dymamic approach. Part B, New York: $M$ Dekker, 1982; 1303-20.

8 Jofe MA. Detection of lens subluxation in pseudoexfoliation. Arch Ophthalmol 1988; 106: 1032.

9 Wishart PK, Spaeth GL, Poryzees EM. Anterior chamber angle in the exfoliation syndrome. BrF Ophthalmol 1985; 69: 103-7.

10 Dark AJ. Cataract extraction complicated by capsular glaucoma. Brf Ophthalmol 1979; 63: 465-8.

11 Tarkkanen AH. Exfoliation syndrome. Trans Ophthalmol Soc UK 1986; 105: 233-6. 